\title{
New Technologies for Outcome Measures in Retinal Disease: Review from the European Vision Institute Special Interest Focus Group
}

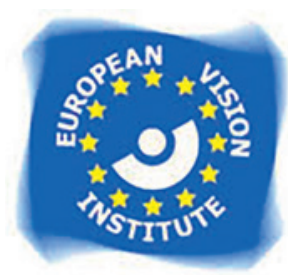

\author{
Maria della Volpe-Waizel ${ }^{a, b} \quad$ Ghislaine L. Traber ${ }^{a, b}$ Peter Malocab \\ Martin Zinkernagel ${ }^{c}$ Ursula Schmidt-Erfurth ${ }^{d}$ Gary Rubin $^{e}$ Botond Roska ${ }^{b}$ \\ Tilman Otto $^{f}$ Richard G. Weleber ${ }^{g}$ Hendrik P.N. Scholl ${ }^{a, b}$ \\ ${ }^{a}$ Department of Ophthalmology, University of Basel, Basel, Switzerland; ${ }^{b}$ Institute of Molecular and Clinical \\ Ophthalmology (IOB), Basel, Switzerland; ' Department of Ophthalmology and Department of Clinical Research, \\ Inselspital, Bern University Hospital, University of Bern, Bern, Switzerland; 'd Medical University of Vienna, \\ Department of Ophthalmology, Vienna, Austria; 'UCL University College London, Institute of Ophthalmology, \\ London, UK; ${ }^{\mathrm{f}} \mathrm{Heidelberg}$ Engineering $\mathrm{GmbH}$, Heidelberg, Germany; ${ }^{9}$ Casey Eye Institute, Departments of \\ Ophthalmology and Molecular and Medical Genetics, University of Oregon Health and Science University, \\ Portland, OR, USA
}

\section{Keywords}

Retina $\cdot$ Retinal disease $\cdot$ Diagnostics $\cdot$ Technologies · Artificial intelligence $\cdot$ Machine learning

\begin{abstract}
Novel diagnostic tools to measure retinal function and structure are rapidly being developed and introduced into clinical use. Opportunities exist to use these informative and robust measures as endpoints for clinical trials to determine efficacy and to monitor safety of therapeutic interventions. In order to inform researchers and clinician-scientists about these new diagnostic tools, a workshop was organized by the European Vision Institute. Invited speakers highlighted the recent advances in state-of-the-art technologies for outcome measures in the field of retina. This review highlights the workshop's presentations in the context of published literature.

(c) 2019 S. Karger AG, Basel
\end{abstract}

\section{Introduction}

A recent Special Interest Focus Group meeting sponsored by the European Vision Institute (EVI) reviewed new technologies for outcome measures in the field of retinal diseases. The Department of Ophthalmology at Basel University in cooperation with the Institute of Molecular and Clinical Ophthalmology Basel (IOB) hosted the meeting, which involved presentations from an international group of scientists and clinicians. The scientific content of this meeting that was focused on selected topics is summarized below in conjunction with a review of published literature within the field.

\section{KARGER}

(c) 2019 S. Karger AG, Basel

E-Mail karger@karger.com

www.karger.com/ore
Hendrik P.N. Scholl, MD, MA

Institute of Molecular and Clinical Ophthalmology (IOB)

Mittlere Strasse 91

$\mathrm{CH}-4031$ Basel (Switzerland)

E-Mail hendrik.scholl@iob.ch 


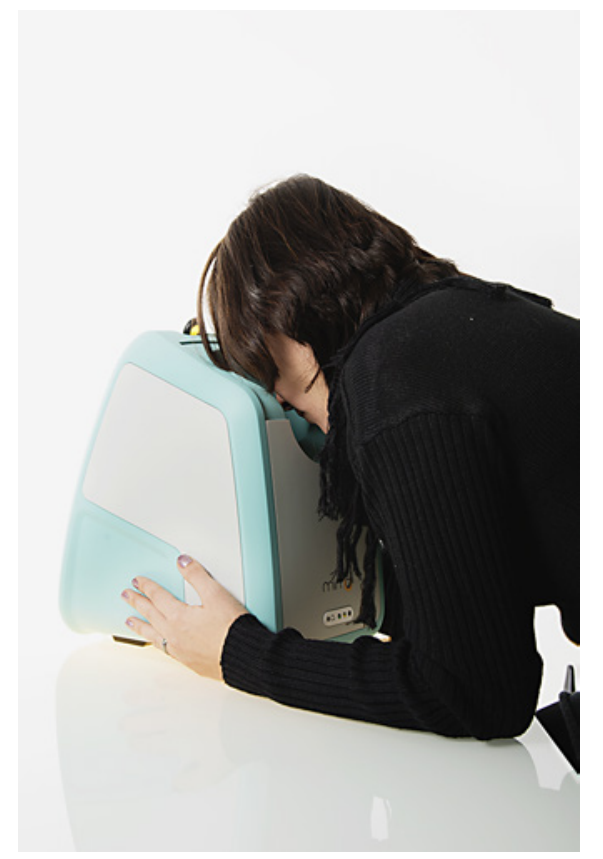

Fig. 1. Study of how a participant can attend a follow-up visit in a self-measuring OCT system for home-use monitoring (MIMOOCT).

\section{Results}

\section{New Developments in Optical Coherence}

Tomography (OCT)

Peter Maloca, MD, started the scientific section of the workshop with an overview on recent OCT developments, such as (1) the Hydra-OCT, (2) the sparse OCT or so-called MIMO-OCT, (3) the three-dimensional speckle denoiser, and (4) the combination of virtual reality (VR) OCT display technology with machine learning.

The Hydra-OCT is a novel dual wavelength coaxial OCT based on the Heidelberg Engineering ${ }^{\circledR}$ Spectralis OCT technology combining two measurements with 870 and 1,060 $\mathrm{nm}$ wavelength, thus leading to a better representation of the retinal and choroidal structures that can provide more information on the specific tissue properties such as the particular refractive index. It has been developed in close collaboration with the team of Christoph Meier at the Institute for Human Centered Engineering (optoLab in Biel, Switzerland).

The MIMO-OCT is a recently developed portable selfmeasuring OCT system that will enable remote retina monitoring, for example for exudative age-related macular degeneration (AMD). Due to its simplified usability, it could also be operated for out-of-office measurements in the future. The most important innovation of the system is the automatic evaluation of the data by a machine learning software enabling an automated decision-supporting regime (Fig. 1) [1,2].

Speckle noise is a granular "noise" that appears in a wide range of medical imaging methods. The three-dimensional speckle denoiser is a novel medical image postprocessing application that can separate signal from speckle noise leading to good structure preservation with high reproducibility, thus smoothening images obtained with OCT and enhancing the visualization of retinal and choroidal structures [3-6].

Finally, the combination of VR technology with OCT is another promising development whereby a multi-user system of up to 4 experts can visualize a three-dimensional OCT scan of the retina at the same time using special VR glasses. In addition, using the supplemental tool Blue $\mathrm{AI}$, it is possible to segment OCT volumes with machine learning tools to provide instant rendering of the VR model. Another aim of these developments is to increase contrast and image quality of the VR models. This way, the VR technology can also be experienced by patients with retinal dystrophies, for example, for a better understanding of their disease [7].

\section{Fluorescence Lifetime Imaging Ophthalmoscopy}

(FLIO)

Martin Zinkernagel, $\mathrm{MD}, \mathrm{PhD}$, summarized the advantages of FLIO, an innovative and noninvasive technique to measure and quantify lifetimes of endogenous retinal autofluorescence. When endogenous fluorophores are excited by photons derived from a monochromatic light source, they gain a higher level of energy before returning to their ground state by emitting photons of longer wavelengths than the exciting light. The average time between excitation and reaching the baseline state can be quantified as the fluorescence lifetime [8].

The system presented by Dr. Zinkernagel is based on the Heidelberg Engineering ${ }^{\circledR}$ Spectralis HRA technology, which uses a picosecond diode laser with $473 \mathrm{~nm}$ wavelength and $80 \mathrm{~Hz}$ sampling rate and two spectral channels (498-560 and 560-720 nm) to detect short and long wavelength signals. The results are presented in two-dimensional color-coded en face images of the retina (Fig. 2). Short lifetimes are coded as red pixels (e.g., in the macular region), while blue pixels represent long lifetimes (e.g., the optic nerve) [9].

The signals measured with FLIO have been shown to be derived from macular pigment as lutein and zeaxanthin [10]. Therefore, FLIO could be used as a sensitive 

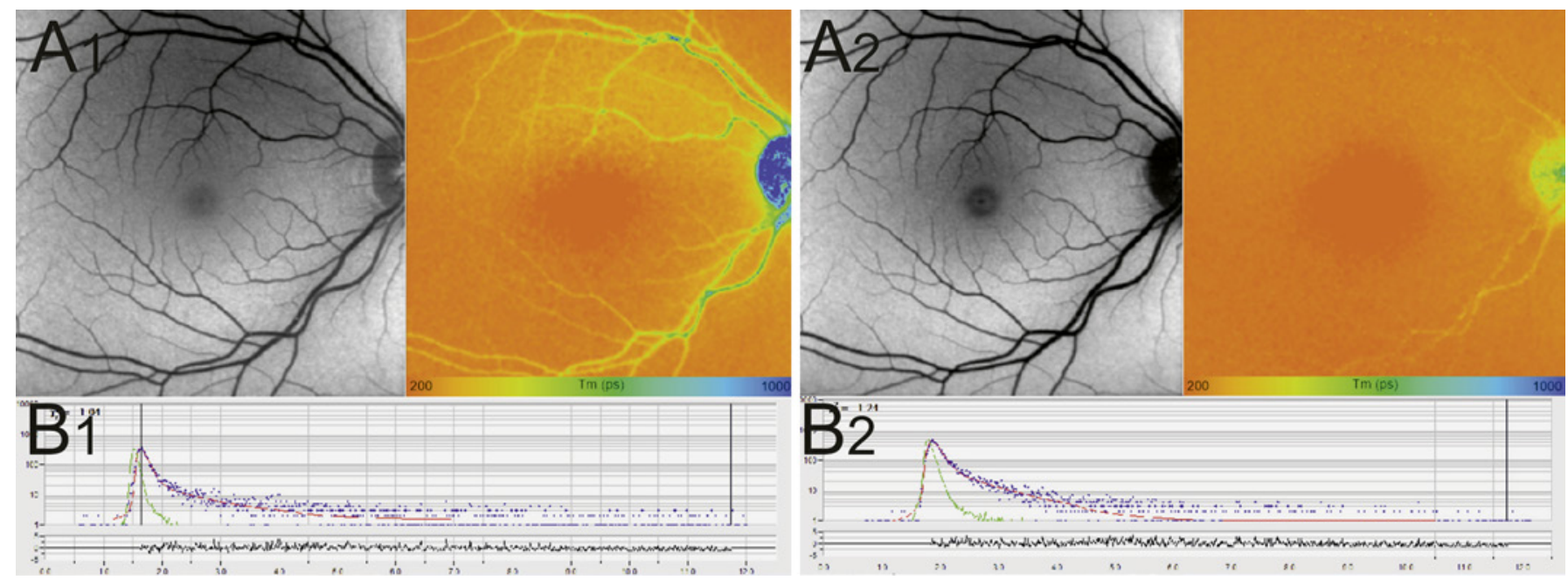

Fig. 2. Representative fluorescence lifetime imaging (FLIO) of a healthy retina. A1 Fundus autofluorescence intensity image (left) and color-coded FLIO image with a mean lifetime range between 200 ps (red color) and 1,000 ps (blue color) for the short spectral channel $(498-560 \mathrm{~nm})$ and for the long spectral channel (560-720 nm). B1, B2 Instrument response curve (green) and corresponding calculated biexponential decay curves (red) over the time interval of $12 \mathrm{~ns}$ for individual pixel locations (modified from [8]).

diagnostic tool to monitor disease progression or therapy success for retinal diseases involving the macular pigment, such as geographic atrophy in dry AMD [11] or macular teleangiectasia [10]. Furthermore, FLIO may be used to quantify visual cycle byproducts and therefore possibly viable photoreceptors in various retinal diseases such as central serous chorioretinopathy [12], retinitis pigmentosa [13], choroideremia [14], or Stargardt disease [15].

\section{Artificial Intelligence in Retinal Imaging}

Ursula Schmidt-Erfurth, MD, next communicated about the importance of machine learning and the usage of artificial intelligence in the field of retinal diagnostics. Since AMD or diabetic retinopathy are leading causes for blindness in the Western civilization nowadays, many centers for retinal diseases are dealing with huge data masses derived from OCTs or other imaging modalities. It is therefore inevitable to find reasonable strategies to detect the relevant information from the big data without the loss of important information [16].

One possible strategy that has been proven to be successful is deep learning, which allows for example the automated detection of intraretinal or subretinal fluid in OCT scans [17-20]. With such processing algorithms it is nowadays possible to have an automated segmentation of the image that allows for quantification, a detection of patterns, structure and/or function correlations, evalua- tion of the disease progression, and even fully automated prediction models for disease progression $[18,19]$.

As an example for a successful clinical application of machine learning algorithms, a prediction model for anti-VEGF treatment was presented that was based on data from the Harbor clinical trial [21]. In this study, 1,097 eyes with neovascular AMD were randomized in four different study arms, which compared pro re nata treatment with ranibizumab to monthly applied injections in two different dosages. With artificial intelligence algorithms, it was not only possible to have fully automated detection of fluid, which is a marker for disease activity, but also to use all extracted features to show that intraretinal fluid accounts for visual loss and, thus, makes a big step towards image-guided treatment management for neovascular AMD for the future [21]. Another example was the automated detection of drusen and drusen-related hyperreflective foci and their corresponding progression prediction models $[22,23]$. These features allow detection of "morphological fingerprints" that can predict whether the individual patient has a high risk of developing geographical atrophy or choroidal neovascularization [23].

All of these advances show that deep learning promises benefits over manual analysis, even when the latter is performed by a retina specialist [24]. Therefore, with increasing multimodal imaging and more data points in the field of ophthalmology, there is clearly the expectation of greater instances of automatization in the future. 


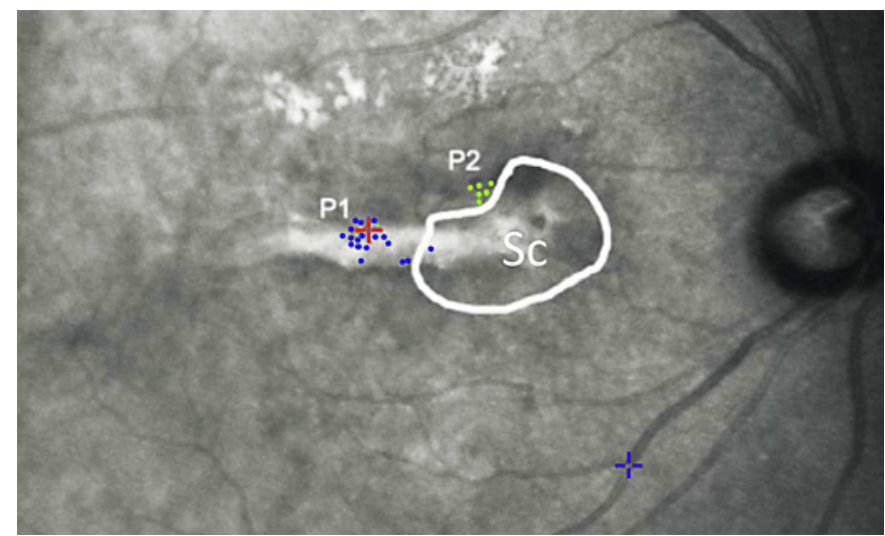

Fig. 3. Example for a patient with multiple preferred retinal loci. A dense central scotoma demarcated by the irregular white curve (labeled Sc) has led this patient to adopt two preferred loci for fixation. The fixation points in $\mathrm{P} 1$ are somewhat more widely scattered than P2, indicating poorer fixation stability. The red cross represents the fixation target and the blue cross is a registration target used to compensate for retinal movement during the fixation trial (not seen by the observer) (modified from [28]).

\section{Visual Function Endpoints in Macular Disease}

\section{Including Microperimetry}

Gary Rubin, $\mathrm{PhD}$, presented an overview on psychophysical testing in general, such as psychophysical tests including visual acuity, contrast sensitivity, visual field testing, stereo and motion tests, and visual performance tests that include reading, face, or object recognition and visual navigation. He pointed out the importance of an appropriate selection for tests before performing a trial in order to avoid controversies about the functional outcomes. In this context, microperimetry (MP) has already been shown to be a valuable tool for possible outcome measures. MP (also called retinal-guided perimetry) was developed from the scanning laser ophthalmoscope, which for the first time allowed projection of the test image onto the corresponding retinal area [25]. MP has come a long way in the current instruments, which now include an infrared eye-tracking system overlaid on highresolution fundus images and provide reproducible results of retinal sensitivity on user-created test grids and fixation bitmaps [26]. However, there remain some technical issues regarding the limited dynamic range and the documentation of the speed used during eye tracking, which need to be resolved in the future. Also, readily accessible normative data sets are not universally available for all microperimeters.

Dr. Rubin further demonstrated the value of MP in clinical applications: eccentric viewing training (EVT) or low vision assistance, as it has been called in the Eccentric Fixation from Enhanced Clinical Training (EFFECT) trial. EVT is a special training for patients with a central scotoma to help them learn to use an extrafoveal area as their new preferred retinal locus (PRL) and has been successfully used in Europe, USA, and the Middle East over the past 25 years [27, 28] (see Fig. 3). Investigations with MP have shown that an optimal use of the PRL depends not only on the location, but also on fixation stability and efficient scanning strategies. The EFFECT trial was a randomized investigation on 200 patients with a central scotoma. One group of 100 patients received conventional low vision services without EVT and 100 received 3 sessions of EVT. For the majority of patients who did not receive EVT, a PRL was established within 6 months, consistent with prior findings [29]. Unfortunately, patients who did receive EVT failed to show any significant benefits, either in terms of self-reported visual ability or measured reading performance.

Another important application of MP is the generation of endpoints to assess efficacy and monitor safety of gene therapy. Biallelic pathogenic mutations of the RPE65 gene cause Leber's congenital amaurosis (LCA) and early-onset retinitis pigmentosa [30]. Recently, clinical trials of subretinal delivery of an AAV vector containing a normal copy of the RPE65 gene to the treated eye of patients with RPE65-deficient retinal disease used MP as an outcome measure. A higher level of retinal sensitivity could be demonstrated in participants with both RPE65-related LCA and early-onset retinitis pigmentosa after this novel gene augmentation treatment $[31,32]$. MP is recommended whenever a photopic visual field measurement is needed, both in clinical practice and in research trials. MP has particular advantage over standard automated perimetry when the remaining visual field sensitivity is limited to the macular region.

\section{$V$. Advantages of Induced Pluripotent Cell (iPS) Technology and Retinal Organoids}

Botond Roska, MD, $\mathrm{PhD}$, next communicated on the different types of neuronal cells that can be found in the retina and pointed out that every single cell type has a different gene expression. Therefore, in order to develop therapies for targeting these different cell types, both their anatomical structure and mechanisms have to be well understood beforehand.

The function of the human retina can be explored by recording neuronal activity with arrays of 30,000 electrodes in retinal slices. Even when disconnected from the brain, it is still possible to record light response of thou- della Volpe-Waizel et al. 
Fig. 4. Retinal disease-associated genes in adult cell types. The cluster heat map of disease-associated genes indicates high expression values marked in purple. This map shows that specific genes (shown on the $y$ axis) that are well known to be related with inherited retinal diseases are predominantly expressed in specific cell types (shown on the $x$ axis), such as photoreceptors, horizontal cells, bipolar cells, amacrine cells, ganglion cells, or microglia. This information is essential for the development of a targeted gene therapy for specific mutations. Note that the Crh cell group (amacrine cells) has been removed from the analysis, the plot area is white (modified from [35]).

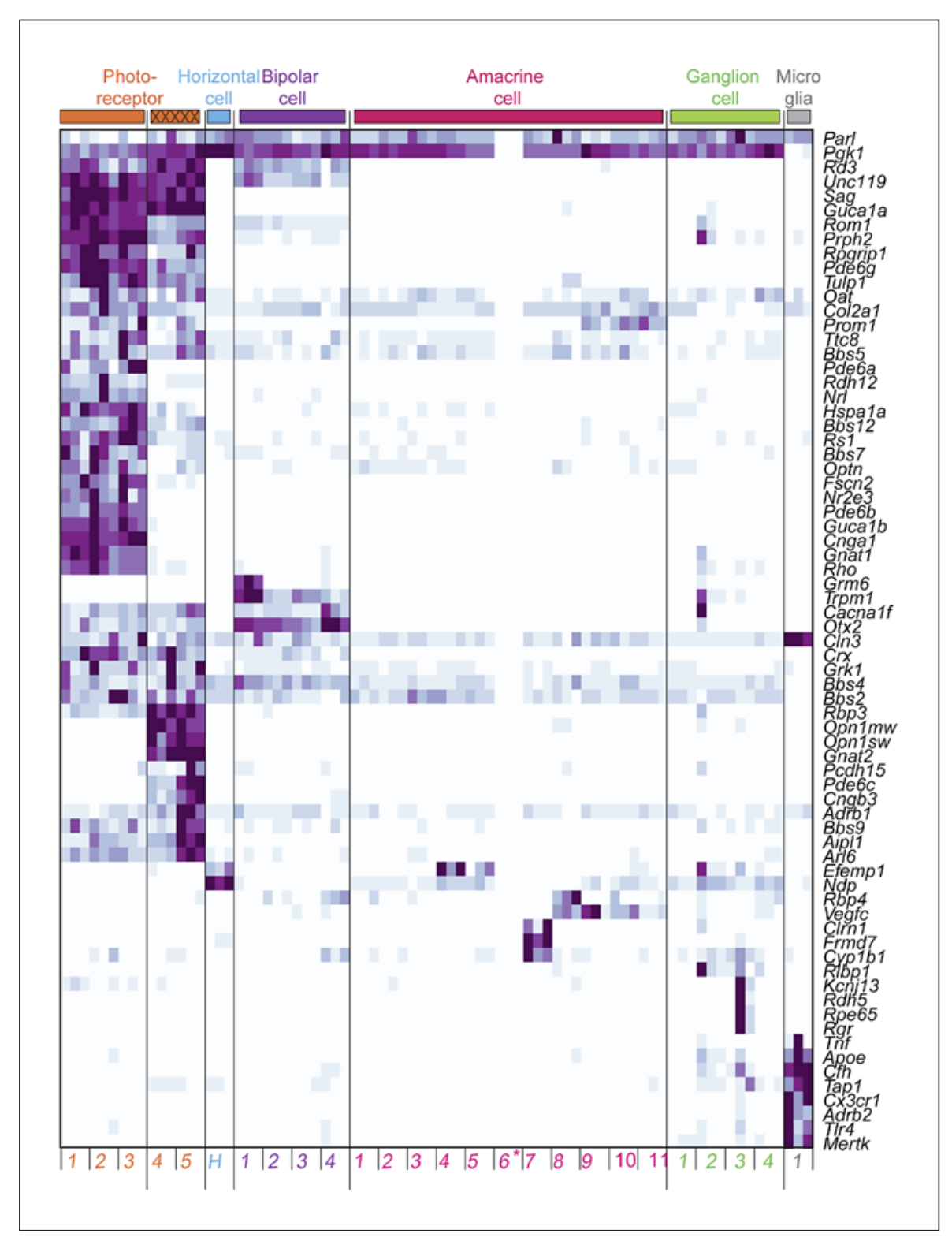

sands of retinal ganglion cells as spike trains within the first 10 minutes after preparation. By clustering these signals with spike sorting, different functional types of retinal ganglion cells can be extracted and classified according to their specific function [33]. Furthermore, these cells can be described with gene sequencing. Knowing both the function and the genetic basis and physiology for the function allows for a detailed description connecting the different cell types and gene mutations to certain retinal diseases in a holistic disease map [34, 35] (Fig. 4).

Once the human retina is understood, the next step would be the development of an artificial humanoid retina. Thus far, there have been approaches that use skin biopsies or blood samples to create retinal tissue in a dish. After "reprogramming" these human pluripotent cells (iPS), photoreceptors and ganglion cells can be cultivated [36]. Up to now, these trials have produced single cell types but not a complete retinal structure. A more recent approach is the development of human retinal organoids with iPS cells [37]. Not only can these organoids be shown to include all cell types that are found in the retina, but they also present axonal growth of the ganglion cells that might form a primitive optic nerve [38]. Interestingly, these organoids stabilize their gene expression and thus their development after around 30 weeks, which corresponds almost precisely to the human fetal development in vivo. 


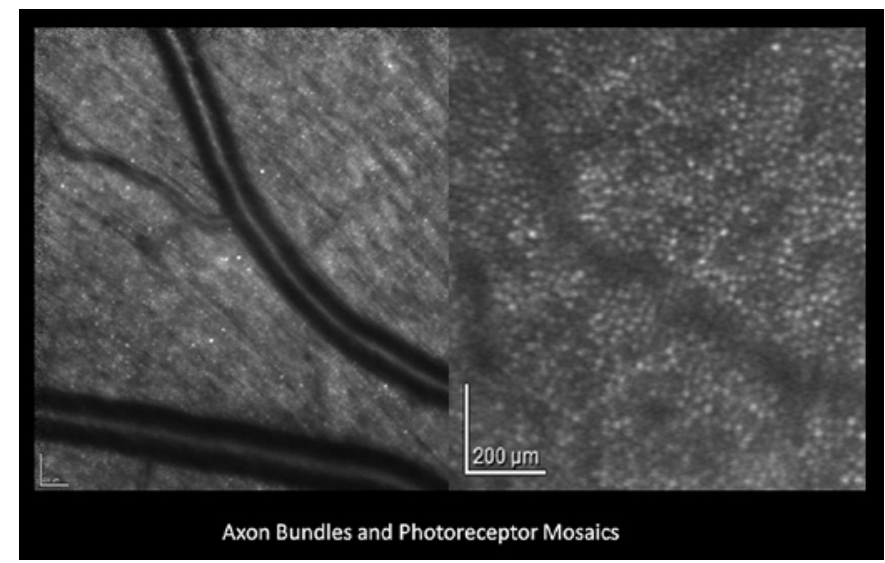

Fig. 5. High magnification module for Heidelberg Engineering Spectralis ${ }^{\circledR}$. With a very high resolution of $1.5 \mu \mathrm{m}$ of tissue per pixel on an $8 \times 8^{\circ}$ field of view, it is now possible to visualize the axon bundles or the retinal photoreceptor mosaic with confocal scanning laser ophthalmoscopy.

Such organoids offer the opportunity to develop in vitro disease models, e.g., for retinal dystrophies such as Stargardt disease, and to apply gene therapy by targeting each of the different cell types with specific vectors. Although these organoids do not provide identical physiological processes in the outer retina compared to in vivo, such as the visual cycle, photoreceptor outer segment disc shedding, and phagocytosis, they are very promising tools to assess, for example, mutational effects on mRNA level in photoreceptors. The clear advantage of iPS cell organoids over cell cultures is the possibility to test novel therapeutic concepts in vitro, even if this requires a complex system that mimics the tissue interaction within an organ. Also, the usage of these organoids will allow reducing the need of animal experiments in the future. In addition, another promising approach is the use of magnetic nanoparticles on the surface to allow for the precise positioning of vectors within the target tissue [39].

\section{Advancements in Diagnostic Imaging Modalities}

Tilman Otto, $\mathrm{PhD}$, presented an overview of existing retinal imaging methods and reported on the newest developments differentiating between different single- or two-photon interactions between the light and tissue.

As for the single-photon interactions, backscattering mechanisms are being used in the fundus camera, as well in the scanning laser ophthalmoscope and OCT. Within this field, there have been various recent developments for two-dimensional devices, such as retinal oximetry. By using two different wavelengths, retinal oximetry represents a spectrophotometric measurement that, when performed with a fundus camera, can differentiate simultaneously between oxygenated and deoxygenated hemoglobin, hence enabling measurement of the oxygen saturation level in retinal vessels. This method allows for investigations on the oxygen metabolism of the human retina with a contact-free and noninvasive measurement [40-44]. With the usage of three different wavelengths, it is possible to capture multicolor images of the retina, a feature that is now standard in many Heidelberg Engineering ${ }^{\circledR}$ devices. Using multispectral imaging with more than three wavelengths is technically possible but currently not used in ophthalmology. Another new development is the high-magnification module for Heidelberg Engineering Spectralis ${ }^{\circledR}$, which offers higher lateral scanning laser ophthalmoscope resolution. On an $8 \times 8^{\circ}$ field of view, each pixel can resolve up to $1.5 \mu \mathrm{m}$ of tissue, which therefore allows visualization of the retinal photoreceptor mosaic (Fig. 5). In addition, this measurement can be performed well even without dilation.

In the field of three-dimensional imaging, various new approaches have been made, one of which is quantitative OCT angiography. By using Doppler signals, this new approach makes it possible to measure the blood flow in the retinal vessels, thus providing more insight into the global blood supply of the retina, potentially helping to evaluate the elasticity of the vessels and detect areas that might be at risk for ischemia [43]. Another very interesting advancement is OCT polarimetry, which determines the polarization uniformity function, which results from the strong scattering effect from tissues such as the retinal pigment epithelium. The degree of scattering can be determined and, in doing so, polarization-sensitive OCT can be used to visualize retinal fibrosis $[45,46]$. With the development of the visible light OCT that uses the full RGB spectrum between 400 and $700 \mathrm{~nm}$ wavelength, an axial resolution of $0.7 \mu \mathrm{m}$ and true-color OCT B scans can be achieved, at least in animal eyes [47]. One very promising advancement is the functional OCT, which is a noninvasive measurement of spatially and temporally resolved changes in the optical path length of the photoreceptor outer segment as a response to an optical stimulus. In the living human eye, functional OCT thus provides information related to the integrity of the neuronal photoreceptor activity of single cones. Therefore, this diagnostic tool can provide insights into the visual phototransduction in vivo [48].

Further, fluorescence mechanisms are also used for several diagnostic tools. Using a single wavelength, fun- della Volpe-Waizel et al. 


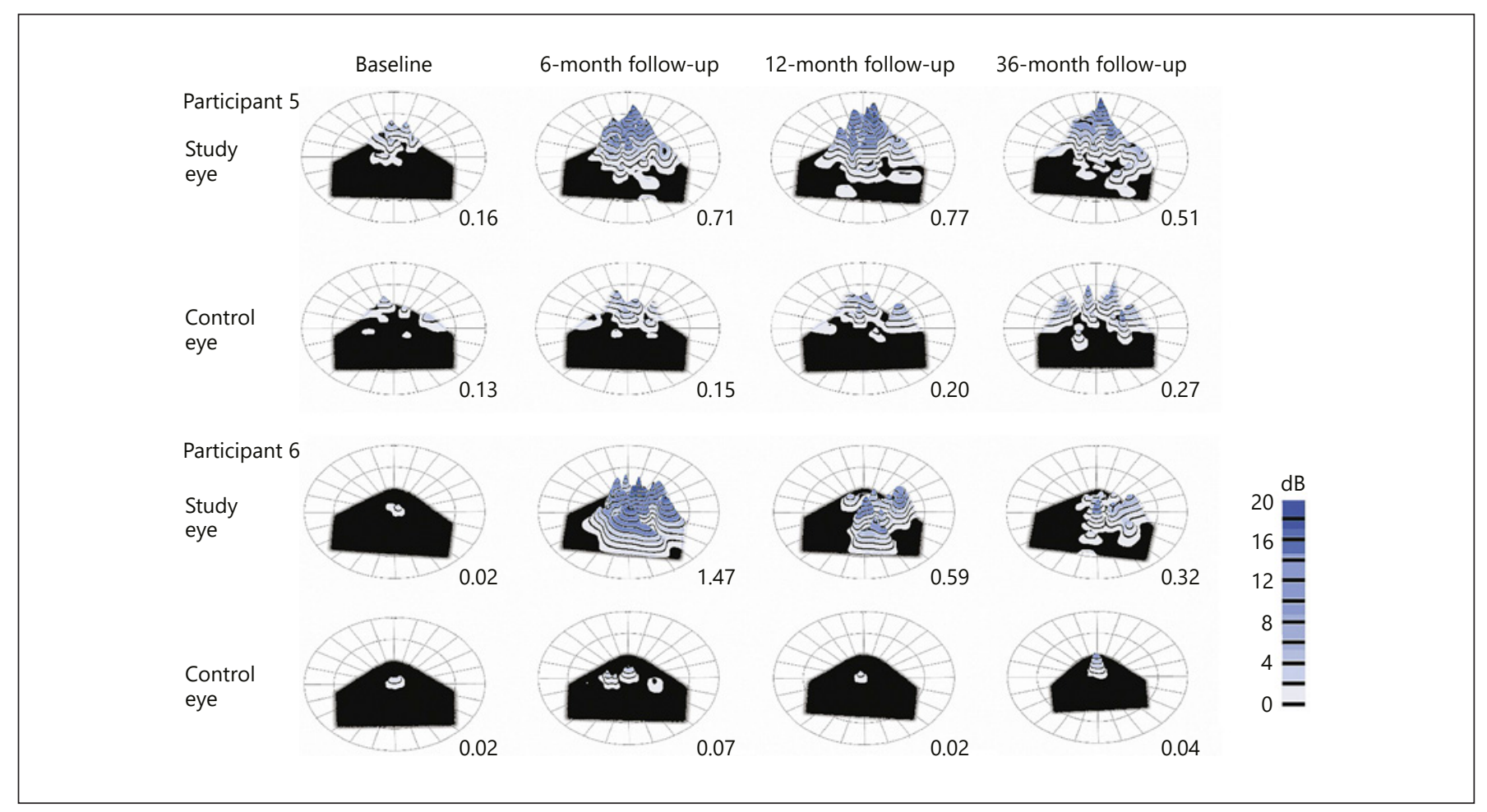

Fig. 6. Appearance of the topographical 3-dimensional HOV models on participants of the RPE65 gene therapy clinical trial reported by Bainbridge et al. [31]. Presented are the long-term results of participants 5 and 6 for both the treated (study) eye and the untreated (control/fellow) eye. Black regions indicate no measurable retinal sensitivity. The calibration scale on the lower right denotes the variable sensitivity (in decibels) at each test location in the test

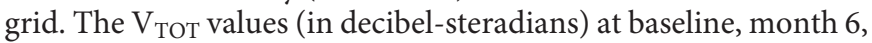
month 12, and month 36 are shown below and to the right of each model. For a normal subject, if the sensitivity at all points in the

dus autofluorescence can be captured. With two wavelengths, quantitative autofluorescence can be used to measure the macular pigment optical density, which is used mostly in research to evaluate macular physiology [49].

As for the two-photon interactions, there is currently ongoing research on the two-photon fluorescence that measures simultaneously two photons and the emission of one photon with higher energy than each initial photon. This technique can be used for a depth-resolved fluorescence measurement that is, in addition, very comfortable for the patients since it uses infrared light. Another interesting tool for future studies might be the fiber-based two-photon FLIO, which has been shown to enable in vivo imaging of the retinal ganglion cells in Thy1 YFP mouse eyes [50].

New Technologies for Outcome Measures in Retina test grid were at the ceiling (maximum of $20 \mathrm{~dB}$ ) - as is often the case among young normal subjects - the total volume $V_{\text {TOT }}$ would equal $5.67 \mathrm{~dB}$-sr. Note that participant 5 (top row) shows an increase in the volume of the hill of vision for the treated eye at 6 months and 12 months, followed by a slight decrease in sensitivity at 36 months. Participant 6 (bottom row) shows a more dramatic increase in sensitivity in the treated eye at 6 months, followed by a steeper decline in sensitivity out to 36 months (modified from [31], Supplemental Appendix, Figure S2).

\section{Modeling and Analysis of the Hill of Vision of}

Static Perimetry (Visual Field Modeling Analysis)

Hendrik Scholl, MD, with material provided by Richard G. Weleber, MD, summarized the visual field modeling analysis (VFMA), which was developed for a better understanding of visual field testing. This diagnostic tool creates hill of vision (HOV) sensitivity surfaces, provides interactive three-dimensional HOV maps for visualization, and provides a unified framework for volumetric visual field analysis [51-53]. VFMA is widely distributed for clinical and research purposes and has been used for several clinical trials investigating both the natural history and clinical trials assessing the response to gene therapy of X-linked juvenile retinoschisis, achromatopsia, LCA, choroideremia, Stargardt disease, and Usher syndrome [31, 54-62], and oral valpro- 
ic acid as a treatment for autosomal dominant retinitis pigmentosa [63].

VFMA first constructs the HOV sensitivity surfaces from the $x, y, z$ data exported from a standard automated perimeter or microperimeter. The $x$ and $y$ values are the coordinates in visual space (for standard automated perimeter) or the retinal surface (for microperimeter) of all test locations in the test grid and form the base of the HOV. The $z$ values are the differential luminous values or sensitivity values as determined at each test site by the thresholding algorithm. VFMA then creates a high-resolution bitmap of the surface of the HOV through interpolation and calculates the volume of sensitivity for the HOV below the sensitivity surface (in units decibel-steradians) (Fig. 6). Using the sensitivity surface, the sensitivity can be assessed by interpolation anywhere within the area of the test grid, not just at the original $(x, y)$ locations. VFMA creates a unique endpoint that differs from conventional perimetry in important ways: conventional perimetry endpoints, such as the mean sensitivity (MS) and mean defect or deficiency (MD) have units of decibels and are unidimensional averaged sensitivity values for all test sites. VFMA, on the other hand, produces a volumetric endpoint, which can be assessed in any region of interest, for example the volume of the whole field $\left(\mathrm{V}_{\text {TOT }}\right)$ or that of the central $30^{\circ}$ field, or through custom selections of any portion of the HOV sensitivity surface. These regions of interest can be defined mathematically, such as circles, sectors, or by isosensitivity lines, or by regions of interest, such as the subretinal bleb created by gene therapy delivery or structural or physiological region, such as the ellipsoid zone or the ring of hyperautofluorescence seen in retinitis pigmentosa. With the decibel-steradian volumetric measure, visual function can be represented as a physical amount instead of an average value. Volumetric endpoints are more meaningful for assessing how much visual function has been gained or lost than comparing mean values.

Another advantage of VFMA is that, unlike conventional endpoints, such as MS and MD, the HOV volume is consistent and comparable across different protocols and with grids of both polar and cartesian design (whereas when calculated from radially oriented grids, MS and MD values represent weighted averages). Depending on the size or view of the grid that was tested, conventional measures, such as MS, produce two different numbers for the same patient. In these ways, the sensitivity volume created by VFMA is more robust to differences in the exam grid. Thus, VFMA permits a comparison of data acquired from patients using different grids and even from different devices, such as full-field static perimetry, standard automat- ed perimetry as the Humphrey Field Analyzer, or modified 2-color scotopic perimetry as for example the Octopus 900 Pro or MP (e.g., Nidek MP-1, Nidek MP-3, MAIA).

In summary, VFMA is a systemic framework for processing visual field sensitivity data from any perimetric instrument. The HOV volume is a unique and robust measure of the quantity of visual function and allows for flexible targeting of any region of interest, stronger and more focused endpoints, and compelling three-dimensional visualizations for research and clinical use.

\section{Summary}

The workshop sponsored by the EVI highlighted new technologies for outcome measures in the retina. Various promising diagnostic developments have been shown and are summarized in this review. Future meetings organized by the EVI will not only focus on new advancements of retinal imaging but also on the anterior segment.

\section{Acknowledgement}

The symposium thanks the EVI for support and organization, all of the speakers, and the attendees of the meeting.

\section{Statement of Ethics}

The authors have no ethical conflicts to disclose.

\section{Disclosure Statement}

P. Maloca is owner of intellectual property on speckle noise analysis and the MIMO-OCT discussed in this article and received lecture fees from Heidelberg Engineering ${ }^{\circledR} \mathrm{GmbH}$ and Zeiss. M. Zinkernagel is consultant for Bayer, Novartis, and Allergan and has received grants from Bayer and Boehringer Ingelheim. U. SchmidtErfurth declares to be a consultant for Novartis, Genentech, Boehringer, and Roche. T. Otto declares to be the head of research and development at Heidelberg Engineering ${ }^{\circledR} \mathrm{GmbH}$. G. Rubin declares that he is a consultant for Pixium Vision SA and MeiraGTxz. R.G. Weleber declares financial support from the Foundation Fighting Blindness: Vice-Chair for Scientific Advisory Board (SAB), Member of Executive Scientific Advisory Board (ESAB) (honorarium received); AGTC: SAB, Co-Investigator for three trials: RPE65 LCA, XLRS1, CNGB3 ACHR; Consultant (Past): Oxford-Biomedica, Pfizer, Novartis; Consultant (Current): NightStaRx, QLT, 4D Molecular Therapeutics; Sanofi: Past P.I. and now Co-Investigator for two clinical treatment trials: USHSTAT, STARGEN; Holder of US Patent No. 8,657,446 Visual Field Modeling and Analysis (VFMA). A subset of his presentation material was given at a NEI/FDA Endpoints Workshop on Age-Related Macular Degeneration and Inherited
84

Ophthalmic Res 2020;63:77-87

DOI: $10.1159 / 000501887$ della Volpe-Waizel et al. 
Retinal Disease held at the NEI in November 2016 [63]. H.P.N. Scholl declares financial support from the following sources: Data Monitoring Committee: Genentech Inc./F. Hoffmann-La Roche Ltd (CHROMA and SPECTRI trials); Genzyme Corp./Sanofi, and ReNeuron Group Plc/Ora Inc., Steering Committee: Novo Nordisk (FOCUS trial), Scientific Advisory Board: Astellas Institute for Regenerative Medicine; Gensight Biologics; Intellia Therapeutics, Inc.; Ionis Pharmaceuticals, Inc.; ReNeuron Group Plc/Ora Inc.; Pharma Research and Early Development (pRED) of F. Hoffmann-La Roche Ltd; and Vision Medicines, Inc, Consultancy: Boehringer Ingelheim Pharma GmbH \& Co. KG; Daiichi Sankyo, Inc.; Gerson Lehrman Group; Guidepoint; and Shire, Co-director of the Institute of Molecular and Clinical Ophthalmology Basel (IOB), which is constituted as a non-profit foundation and receives funding from the University of Basel, the University Hospital Basel, Novartis, and the government of Basel-Stadt. M. della Volpe-Waizel received consultation fees from Novartis. Except as noted above, all authors certify that they have no affiliations with or involvement in any organization or entity with any financial interest (such as honoraria; educational grants; participation in speakers' bureaus; membership, employment, consultancies, stock ownership, or other equity interest; nor with any expert testimony or patent-licensing arrangements), or non-financial interest (such as personal or professional relationships, affiliations, knowledge or beliefs) in the subject matter or materials discussed in this article.

\section{Funding Sources}

H.P.N. Scholl was supported by the Swiss National Science Foundation, National Center of Competence in Research "Molecular Systems Engineering," the Wellcome Trust, and the Foundation Fighting Blindness Clinical Research Institute and unrestricted grants from Acucela Inc., Aegerion Pharmaceuticals (Novelion Therapeutics), Kinarus AG; NightstaRx Ltd., Ophthotech Corporation and Spark Therapeutics England, Ltd. M. della VolpeWaizel was supported by unrestricted grant from SAMW (Schweizerische Akademie der Medizinischen Wissenschaften), SNF (Swiss National Science Foundation), and the Bangerter Foundation.

\section{Author Contributions}

M. della Volpe-Waizel, G. Traber, P. Maloca, M. Zinkernagel, U. Schmidt-Erfurth, G. Rubin, B. Roska, T. Otto, R.G. Weleber, and H.P.N. Scholl wrote the manuscript, took part in the revision process, and approved the final submission.

\section{References}

1 Quellec G, Kowal J, Hasler PW, Scholl HPN, Zweifel S, Konstantinos B, et al. Feasibility of support vector machine learning in age-related macular degeneration using small sample yielding sparse optical coherence tomography data. Acta Ophthalmol. 2019 Aug; 97(5):e719-e728.

2 Maloca P, Hasler PW, Barthelmes D, Arnold P, Matthias M, Scholl HP, et al. Safety and Feasibility of a Novel Sparse Optical Coherence Tomography Device for Patient-Delivered Retina Home Monitoring. Transl Vis Sci Technol. 2018 Jul;7(4):8.

3 Maloca PM, Spaide RF, Rothenbuehler S, Scholl HPN, Heeren T, Ramos de Carvalho JE, et al. Enhanced resolution and specklefree three-dimensional printing of macular optical coherence tomography angiography. Acta Ophthalmol. 2019 Mar;97(2):e317e319.

4 Maloca P, Gyger C, Hasler PW. A pilot study to image the vascular network of small melanocytic choroidal tumors with speckle noisefree 1050-nm swept source optical coherence tomography (OCT choroidal angiography). Graefes Arch Clin Exp Ophthalmol. 2016 Jun; 254(6):1201-10.

5 Maloca P, Gyger C, Schoetzau A, Hasler PW. Ultra-Short-Term Reproducibility of Speckle-Noise Freed Fluid and Tissue Compartmentalization of the Choroid Analyzed by Standard OCT. Transl Vis Sci Technol. 2015 Nov 17;4(6):3.

New Technologies for Outcome Measures in Retina
6 Gyger C, Cattin R, Hasler PW, Maloca P. Three-dimensional speckle reduction in optical coherence tomography through structural guided filtering. Opt Eng. 2014;53(7):073105.

7 Maloca PM, de Carvalho JER, Heeren T, Hasler PW, Mushtaq F, Mon-Williams M, Scholl HPN, Balaskas K, Egan C, Tufail A, Witthauer L, Cattin PC. High-Performance Virtual Reality Volume Rendering of Original Optical Coherence Tomography Point-Cloud Data Enhanced With Real-Time Ray Casting. Transl Vis Sci Technol. 2018 Jul 9;7(4):2.

8 Dysli C, Wolf S, Berezin MY, Sauer L, Hammer M, Zinkernagel MS. Fluorescence lifetime imaging ophthalmoscopy. Prog Retin Eye Res. 2017 Sep;60:120-43.

9 Dysli C, Dysli M, Enzmann V, Wolf S, Zinkernagel MS. Fluorescence lifetime imaging of the ocular fundus in mice. Invest Ophthalmol Vis Sci. 2014 Sep;55(11):7206-15.

10 Sauer L, Andersen KM, Li B, Gensure RH, Hammer M, Bernstein PS. Fluorescence Lifetime Imaging Ophthalmoscopy (FLIO) of Macular Pigment. Invest Ophthalmol Vis Sci. 2018 Jun;59(7):3094-103.

11 Dysli C, Wolf S, Zinkernagel MS. Autofluorescence Lifetimes in Geographic Atrophy in Patients With Age-Related Macular Degeneration. Invest Ophthalmol Vis Sci. 2016 May; 57(6):2479-87.

12 Dysli C, Berger L, Wolf S, Zinkernagel MS. Fundus autofluorescence lifetimes and central serous chorioretinopathy. Retina. 2017 Nov;37(11):2151-61.
13 Dysli C, Schürch K, Pascal E, Wolf S, Zinkernagel MS. Fundus Autofluorescence Lifetime Patterns in Retinitis Pigmentosa. Invest Ophthalmol Vis Sci. 2018 Apr;59(5):1769-78.

14 Dysli C, Wolf S, Tran HV, Zinkernagel MS Autofluorescence Lifetimes in Patients With Choroideremia Identify Photoreceptors in Areas With Retinal Pigment Epithelium Atrophy. Invest Ophthalmol Vis Sci. 2016 Dec; 57(15):6714-21.

15 Dysli C, Wolf S, Hatz K, Zinkernagel MS. Fluorescence Lifetime Imaging in Stargardt Disease: Potential Marker for Disease Progression. Invest Ophthalmol Vis Sci. 2016 Mar; 57(3):832-41.

16 Schmidt-Erfurth U, Sadeghipour A, Gerendas BS, Waldstein SM, Bogunović H. Artificial intelligence in retina. Prog Retin Eye Res. 2018 Nov;67:1-29.

17 Montuoro A, Waldstein SM, Gerendas BS, Schmidt-Erfurth U, Bogunović H. Joint retinal layer and fluid segmentation in OCT scans of eyes with severe macular edema using unsupervised representation and auto-context. Biomed Opt Express. 2017 Feb;8(3):1874-88.

18 Niu S, de Sisternes L, Chen Q, Rubin DL, Leng T. Fully automated prediction of geographic atrophy growth using quantitative spectraldomain optical coherence tomography biomarkers. Ophthalmology. 2016 Aug;123(8): 1737-50. 
19 Schlegl T, Waldstein SM, Bogunovic H, Endstraßer F, Sadeghipour A, Philip AM, et al. Fully automated detection and quantification of macular fluid in OCT using deep learning. Ophthalmology. 2018 Apr;125(4):549-58.

20 Schmidt-Erfurth U, Waldstein SM. A paradigm shift in imaging biomarkers in neovascular age-related macular degeneration. Prog Retin Eye Res. 2016 Jan;50:1-24.

21 Bogunovic H, Waldstein SM, Schlegl T, Langs G, Sadeghipour A, Liu X, et al. Prediction of Anti-VEGF Treatment Requirements in Neovascular AMD Using a Machine Learning Approach. Invest Ophthalmol Vis Sci. 2017 Jun; 58(7):3240-8.

22 Schlanitz FG, Baumann B, Kundi M, Sacu S, Baratsits M, Scheschy U, et al. Drusen volume development over time and its relevance to the course of age-related macular degeneration. Br J Ophthalmol. 2017 Feb;101(2):198203.

23 Schmidt-Erfurth U, Waldstein SM, Klimscha S, Sadeghipour A, Hu X, Gerendas BS, et al. Prediction of Individual Disease Conversion in Early AMD Using Artificial Intelligence. Invest Ophthalmol Vis Sci. 2018 Jul;59(8): 3199-208.

24 De Fauw J, Ledsam JR, Romera-Paredes B, Nikolov S, Tomasev N, Blackwell S, et al. Clinically applicable deep learning for diagnosis and referral in retinal disease. Nat Med. 2018 Sep;24(9):1342-50.

25 Timberlake GT, Mainster MA, Peli E, Augliere RA, Essock EA, Arend LE. Reading with a macular scotoma. I. Retinal location of scotoma and fixation area. Invest Ophthalmol Vis Sci. 1986 Jul;27(7):1137-47.

26 Palkovits S, Hirnschall N, Georgiev S, Leisser C, Findl O. Test-Retest Reproducibility of the Microperimeter MP3 With Fundus Image Tracking in Healthy Subjects and Patients With Macular Disease. Transl Vis Sci Technol. 2018 Feb 7;7(1):17

27 Gaffney AJ, Margrain TH, Bunce CV, Binns AM. How effective is eccentric viewing training? A systematic literature review. Ophthalmic Physiol Opt. 2014 Jul;34(4):427-37.

28 Crossland MD, Culham LE, Kabanarou SA, Rubin GS. Preferred retinal locus development in patients with macular disease. Ophthalmology. 2005 Sep;112(9):1579-85.

29 Petre KL, Hazel CA, Fine EM, Rubin GS. Reading with eccentric fixation is faster in inferior visual field than in left visual field. Optom Vis Sci. 2000 Jan;77(1):34-9.

30 Weleber RG, Michaelides M, Trzupek KM, Stover NB, Stone EM. The phenotype of Severe Early Childhood Onset Retinal Dystrophy (SECORD) from mutations of RPE65 and differentiation from Leber congenital amaurosis. Invest Opthalmol Vis Sci. 2011 Jan 5 52(1):292-302

31 Bainbridge JW, Mehat MS, Sundaram V, Robbie SJ, Barker SE, Ripamonti C, et al. Long-term effect of gene therapy on Leber's congenital amaurosis. N Engl J Med. 2015 May;372(20):1887-97.
32 Maguire AM, Simonelli F, Pierce EA, Pugh EN Jr, Mingozzi F, Bennicelli J, et al. Safety and efficacy of gene transfer for Leber's congenital amaurosis. N Engl J Med. 2008 May; 358(21):2240-8.

33 Drinnenberg A, Franke F, Morikawa RK, Jüttner J, Hillier D, Hantz P, et al. How Diverse Retinal Functions Arise from Feedback at the First Visual Synapse. Neuron. 2018 Jul;99(1): 117-134.e11.

34 Roska B, Sahel JA. Restoring vision. Nature. 2018 May;557(7705):359-67.

35 Siegert S, Cabuy E, Scherf BG, Kohler H, Panda S, Le YZ, Fehling HJ, Gaidatzis D, Stadler MB, Roska B. Transcriptional code and disease map for adult retinal cell types. Nat Neurosci. 2012 Jan 22;15(3):487-95, S1-2

36 Busskamp V, Krol J, Nelidova D, Daum J, Szikra T, Tsuda B, et al. miRNAs 182 and 183 are necessary to maintain adult cone photoreceptor outer segments and visual function. Neuron. 2014 Aug;83(3):586-600.

37 Scholl HP, Strauss RW, Singh MS, Dalkara D, Roska B, Picaud S, et al. Emerging therapies for inherited retinal degeneration. Sci Transl Med. 2016 Dec;8(368):368rv6.

38 Krol J, Roska B. Treatment synergy in axon regeneration. Nat Neurosci. 2016 Jul;19(8): 983-4.

39 Schubert R, Trenholm S, Balint K, Kosche G, Cowan CS, Mohr MA, et al. Virus stamping for targeted single-cell infection in vitro and in vivo. Nat Biotechnol. 2018 Jan;36(1):81-8.

40 Hammer M, Thamm E, Schweitzer D. A simple algorithm for in vivo ocular fundus oximetry compensating for non-hemoglobin absorption and scattering. Phys Med Biol. 2002; 47(17):N233-8.

41 Hammer M, Vilser W, Riemer T, Mandecka A, Schweitzer D, Kühn U, et al. Diabetic patients with retinopathy show increased retinal venous oxygen saturation. Graefes Arch Clin Exp Ophthalmol. 2009 Aug;247(8):1025-30.

42 Waizel M, Türksever C, Todorova MG. Normative values of retinal vessel oximetry in healthy children against adults. Acta Ophthalmol. 2018a Nov;96(7):e828-34.

43 Waizel M, Türksever C, Todorova MG. The effect of autoimmune retinopathy on retinal vessel oxygen saturation. Eye (Lond). 2018b Sep;32(9):1455-62.

44 Liu JJ, Grulkowski I, Kraus MF, Potsaid B, Lu $\mathrm{CD}$, Baumann $\mathrm{B}$, et al. In vivo imaging of the rodent eye with swept source/Fourier domain OCT. Biomed Opt Express. 2013 Feb;4(2): 351-63.

45 Götzinger E, Pircher M, Geitzenauer W, Ahlers C, Baumann B, Michels S, et al. Retinal pigment epithelium segmentation by polarization sensitive optical coherence tomography. Opt Express. 2008 Oct;16(21):16410-22.

46 Michels S, Pircher M, Geitzenauer W, Simader C, Götzinger E, Findl O, et al. Value of polarisation-sensitive optical coherence tomography in diseases affecting the retinal pigment epithelium. Br J Ophthalmol. 2008 Feb;92(2): 204-9.
47 Harper DJ, Augustin M, Lichtenegger A, Eugui $\mathrm{P}$, Reyes $\mathrm{C}$, Glösmann $\mathrm{M}$, et al. White light polarization sensitive optical coherence tomography for sub-micron axial resolution and spectroscopic contrast in the murine retina. Biomed Opt Express. 2018 Apr;9(5): 2115-29.

48 Hillmann D, Spahr H, Pfäffle C, Sudkamp H, Franke G, Hüttmann G. In vivo optical imaging of physiological responses to photostimulation in human photoreceptors. Proc Natl Acad Sci USA. 2016 Nov;113(46):13138-43.

49 Beatty S, Koh HH, Carden D, Murray IJ. Macular pigment optical density measurement: a novel compact instrument. Ophthalmic Physiol Opt. 2000 Mar;20(2):105-11.

50 Kamali T, Fischer J, Farrell S, Baldridge WH, Zinser G, Chauhan BC. Simultaneous in vivo confocal reflectance and two-photon retinal ganglion cell imaging based on a hollow core fiber platform. J Biomed Opt. 2018 Mar;23(9): $1-4$

51 Weleber RG, Smith TB, Peters D, Chegarnov EN, Gillespie SP, Francis PJ, et al. VFMA: Topographic Analysis of Sensitivity Data From Full-Field Static Perimetry. Transl Vis Sci Technol. 2015 Apr;4(2):14

52 Smith TB, Parker M, Steinkamp PN, Weleber RG, Smith N, Wilson DJ; VPA Clinical Trial Study Group; EZ Working Group. StructureFunction Modeling of Optical Coherence Tomography and Standard Automated Perimetry in the Retina of Patients with Autosomal Dominant Retinitis Pigmentosa. PLoS One. 2016 Feb;11(2):e0148022.

53 Smith TB, Smith N, Weleber RG. Comparison of nonparametric methods for static visual field interpolation. Med Biol Eng Comput. 2017 Jan;55(1):117-26.

54 Weleber RG, Pennesi ME, Wilson DJ, Kaushal S, Erker LR, Jensen L, McBride MT, et al. Results at 2 Years after Gene Therapy for RPE65-Deficient Leber Congenital Amaurosis and Severe Early-Childhood-Onset Retinal Dystrophy. Ophthalmology. 2016 Jul; 123(7):1606-20.

55 Subash M, Comyn O, Samy A, Qatarneh D, Antonakis S, Mehat M, et al. The Effect of Multispot Laser Panretinal Photocoagulation on Retinal Sensitivity and Driving Eligibility in Patients With Diabetic Retinopathy. JAMA Ophthalmol. 2016 Jun;134(6):666-72.

56 Boese EA, Jain N, Jia Y, Schlechter CL, Harding CO, Gao SS, et al. Characterization of Chorioretinopathy Associated with Mitochondrial Trifunctional Protein Disorders: Long-Term Follow-up of 21 Cases. Ophthalmology. 2016 Oct;123(10):2183-95.

57 Lockhart CM, Smith TB, Yang P, Naidu M, Rettie AE, Nath A, et al. Longitudinal characterisation of function and structure of Bietti crystalline dystrophy: report on a novel homozygous mutation in CYP4V2. Br J Ophthalmol. 2018 Feb;102(2):187-94. 
58 Tee JJ, Yang Y, Kalitzeos A, Webster A, Bainbridge J, Weleber RG, et al. Characterization of Visual Function, Interocular Variability and Progression Using Static Perimetry-Derived Metrics in RPGR-Associated Retinopathy. Invest Ophthalmol Vis Sci. 2018 May; 59(6):2422-36.

59 Mehat MS, Sundaram V, Ripamonti C, Robson AG, Smith AJ, Borooah S, et al. Transplantation of Human Embryonic Stem CellDerived Retinal Pigment Epithelial Cells in Macular Degeneration. Ophthalmology. 2018 Nov;125(11):1765-75.
60 Kumaran N, Rubin GS, Kalitzeos A, Fujinami $\mathrm{K}$, Bainbridge JW, Weleber RG, et al. A CrossSectional and Longitudinal Study of Retinal Sensitivity in RPE65-Associated Leber Congenital Amaurosis. Invest Ophthalmol Vis Sci. 2018 Jul;59(8):3330-9.

61 Pennesi ME, Weleber RG, Yang P, Whitebirch C, Thean B, Flotte TR, Humphries M, et al. Results at 5 Years After Gene Therapy for RPE65-Deficient Retinal Dystrophy. Hum Gene Ther. 2018 Jul 24. doi: 10.1089/ hum.2018.014. [Epub ahead of print].
62 Birch DG, Bernstein PS, Iannacone A, Pennesi ME, Lam BL, Heckenlively J, et al. Effect of Oral Valproic Acid vs Placebo for Vision Loss in Patients With Autosomal Dominant Retinitis Pigmentosa: A Randomized Phase 2 Multicenter Placebo-Controlled Clinical Trial. JAMA Ophthalmol. 2018 Aug;136(8):84956.

63 Csaky K, Ferris F 3rd, Chew EY, Nair P, Cheetham JK, Duncan JL. Report from the NEI/FDA Endpoints Workshop on age-related macular degeneration and inherited retinal diseases. Invest Ophthalmol Vis Sci. $2017 \mathrm{Jul}$; 58(9):3456-63. 